\title{
Suppression of Microglial Activation Is Neuroprotective in a Mouse Model of Human Retinitis Pigmentosa
}

\author{
(1) Bo Peng, ${ }^{1}$ Jia Xiao, ${ }^{1,4}$ Ke Wang, ${ }^{1}$ Kwok-Fai So, ${ }^{2,3}$ George L. Tipoe, ${ }^{1}$ and Bin Lin ${ }^{1,2,3}$ \\ ${ }^{1}$ Department of Anatomy, ${ }^{2}$ Department of Ophthalmology, and ${ }^{3}$ State Key Laboratory of Brain and Cognitive Sciences, The University of Hong Kong, Li Ka \\ Shing Faculty of Medicine, Pokfulam, Hong Kong, and ${ }^{4}$ Department of Immunobiology, Institute of Tissue Transplantation and Immunology, Jinan \\ University, 510632 Guangzhou, China
}

\begin{abstract}
Retinitis pigmentosa (RP) is a photoreceptor-degenerative disease caused by various mutations and is characterized by death of rod photoreceptor cell followed by gradual death of cone photoreceptors. The molecular mechanisms that lead to rod and cone death are not yet fully understood. Neuroinflammation contributes to the progression of many chronic neurodegenerative disorders. However, it remains to be determined how microglia contribute to photoreceptor disruption in RP. In this study, we explored the role of microglia as a contributor to photoreceptor degeneration in the rd10 mouse model of RP. First, we demonstrated that microglia activation was an early alteration in RP retinas. Inhibition of microglia activation by minocycline reduced photoreceptor apoptosis and significantly improved retinal structure and function and visual behavior in rd10 mice. Second, we identified that minocycline exerted its neuroprotective effects through both anti-inflammatory and anti-apoptotic mechanisms. Third, we found that $C x 3 c r 1$ deficiency dysregulated microglia activation and subsequently resulted in increased photoreceptor vulnerability in $\mathrm{rd} 10 \mathrm{mice}$, suggesting that the $C \times 3 \mathrm{cl} / \mathrm{C} \times 3 \mathrm{cr} 1 \mathrm{signaling}$ pathway might protect against microglia neurotoxicity. We concluded that suppression of neuroinflammatory responses could be a potential treatment strategy aimed at improving photoreceptor survival in human RP.
\end{abstract}

Key words: Cx3cr1; microglia; minocycline; photoreceptor degeneration; rd10 mice

\section{Introduction}

Retinitis pigmentosa (RP) is a photoreceptor-degenerative disease caused by various mutations that result in rod death followed by gradual death of cones (Hartong et al., 2006). However, the molecular mechanisms that lead to rod and cone death are not fully understood. There are currently few effective treatments that can halt or reverse progressive photoreceptor degeneration for human RP. Thus, it becomes critical to investigate what determines the progressive nature of RP, and to develop therapeutic strategies aimed at suppressing its progression. Neuroinflammation is now considered a hallmark of many chronic neurodegenerative disorders (Glass et al., 2010). Microglia mediate an innate immune response and contribute to the progression of diseases (Hanisch and Kettenmann, 2007). However, it remains to be determined how neuroinflammation contributes to photoreceptor degeneration in RP.

Microglia react promptly to a wide variety of neural injuries. On the one hand, microglia function as specialized scavengers

\footnotetext{
Received Dec. 12, 2013; revised April 25, 2014; accepted May 5, 2014

Author contributions: B.P. and B.L. designed research; B.P., J.X., and K.W. performed research; B.P., J.X., K.-F.S., G.L.T., and B.L. analyzed data; B.P., G.L.T. and B.L. wrote the paper.

This work was supported by The University of Hong Kong Seed Funding Program for Basic Research and General Research Fund from the Hong Kong Research Grants Council (772810). We thank Dr. Gary Pickard for critically reading and improving English text and Davy Lee and Guoyin Xiong for technical support.

The authors declare no competing financial interests.

Correspondence should be addressed to Dr. Bin Lin, Department of Anatomy, The University of Hong Kong, Li Ka Shing Faculty of Medicine, 21 Sassoon Road, Pokfulam, Hong Kong. E-mail: blin@hku.hk.

DOI:10.1523/JNEUROSCI.5200-13.2014

Copyright $\odot 2014$ the authors $\quad 0270-6474 / 14 / 348139-12 \$ 15.00 / 0$
}

that eliminate pathogens (Hanisch and Kettenmann, 2007). On the other hand, microglia have been implicated in the pathology of neurodegenerative diseases (Block et al., 2007). Previous studies have shown that microglia activation contributes to Parkinson's and Alzheimer's diseases (Lucin and Wyss-Coray, 2009; Saijo and Glass, 2011). Inherited retinal degeneration is also associated with microglia activation (Langmann, 2007), which is identified in RP animal models and human RP (Roque et al., 1996; Gupta et al., 2003; Zeiss and Johnson, 2004; Zeng et al., 2005; Gehrig et al., 2007; Sasahara et al., 2008; Ebert et al., 2009; Zhou et al., 2011; Sheets et al., 2013; Yoshida et al., 2013a,b). Moreover, microglia activation has been found to coincide with or to precede the occurrence of peak photoreceptor apoptosis in RP (Roque et al., 1996; Gupta et al., 2003; Zeiss and Johnson, 2004; Zeng et al., 2005; Gehrig et al., 2007), suggesting that microglia might play an active role in the pathogenesis of RP. However, the identification of activated microglia in RP retinas does not, in itself, confirm the role of activated microglia in the progression of photoreceptor apoptosis.

In this study, we asked whether activated microglia contributed to RP neurodegenerative process. For this purpose, we used rd10 mice, a well characterized mouse model of RP, to study the role of microglia in photoreceptor apoptosis. To validate the importance of neuroinflammation in RP, minocycline, an inhibitor of microglial activation, was injected into the peritoneum of $\mathrm{rd} 10$ mice. Moreover, chemokine receptor $\mathrm{C} \times 3 \mathrm{crl}$, which is specifically expressed by microglia, has been suggested to play an important role in regulating microglia activation and neuronal 
survival (Meucci et al., 2000; Cardona et al., 2006). It also has been reported that Cx3cr1 deficiency causes pronounced accumulation of activated microglia in retinas, leading to retinal macular degeneration (Combadière et al., 2007). However, it remains unclear whether this signaling pathway contributed to the pathology in RP. We backcrossed Cx3cr1 $1^{\text {GFP/GFP }}$ mice, in which the $C x 3 c r 1$ gene was replaced with a cDNA encoding green fluorescent protein, into the rd10 background, and investigated the effect of CX3cr1 deficiency on microglia activation and photoreceptor survival in $\mathrm{rd} 10$ retinas.

\section{Materials and Methods}

Animals and treatment. Wild-type (WT; C57BL/6J) mice, rd10 mice, and Cx3cr1 $1^{\text {GFP/GFP }}$ mice were obtained from The Jackson Laboratory. Rd10 mice were backcrossed with CX3 $\mathrm{cr} 1^{\text {GFP/GFP }}$ mice, and the littermates from $\mathrm{rd10/C} \times 3 \mathrm{cr} 1^{+/ G F P}$ mice and $\mathrm{rd10/C} \times 3 \mathrm{crl} 1^{\text {GFP/GFP }}$ mice of either sex were used for experiments. Animals were housed on a $12 \mathrm{~h}$ light/dark cycle and maintained at the Laboratory Animal Unit, The University of Hong Kong. All experimental procedures were approved by the Committee on the Use of Live Animals in Teaching and Research at The University of Hong Kong and conducted in accordance with the ARVO statement for the use of animals. The Laboratory Animal Unit of the University of Hong Kong is fully accredited by the Association for Assessment and Accreditation of Laboratory Animal Care International.

Minocycline (Sigma-Aldrich) or vehicle PBS was injected intraperitoneally. $\mathrm{rd} 10$ mice were treated with minocycline $(45 \mathrm{mg} / \mathrm{kg})$ twice daily (12 h apart), starting from postnatal day 13 (P13) and continuing through to $\mathrm{P} 24$ or $\mathrm{P} 29$. Another set of $\mathrm{rd} 10$ mice was similarly prepared to receive intraperitoneal injections of cyclooxygenase (COX)-1 selective inhibitor SC-560 (30 mg/kg; Sigma-Aldrich) or vehicle (24\% DMSO in $0.1 \mathrm{~m}$ phosphate buffer, $\mathrm{pH} 7.4$ ) once a day from P13 to P24.

Immunocytochemistry and confocal imaging. The animals were deeply anesthetized with a mixture of ketamine hydrochloride $(30-40 \mathrm{mg} / \mathrm{kg}$ ) and xylazine $(3-6 \mathrm{mg} / \mathrm{kg})$ at different time points. Eyes were quickly enucleated after a reference point was made to label the superior pole and the retinas were dissected free of vitreous and sclera in carboxygenated Ames' Medium (Sigma-Aldrich), and then fixed in 4\% paraformaldehyde (PFA) in $0.1 \mathrm{~m}$ phosphate buffer, $\mathrm{pH} 7.4$, for $0.5-1 \mathrm{~h}$. Some of the retinas were sectioned serially at a thickness of $10-12 \mu \mathrm{m}$ using a cryostat. Both whole-mounted retinas and cross sections were blocked in a solution containing 3\% normal goat serum (NGS), 1\% bovine serum albumin (BSA), and $0.3 \%$ Triton X-100 in PBS, pH 7.4, for $1 \mathrm{~h}$. Primary antibodies were from rabbit antibody to GFP (1:500, Invitrogen; catalog \#A11122, RRID: AB_10073917), rat anti-mouse CD68 (1:500; AbD Serotec; catalog \#MCA1957, RRID: AB_322219), and rabbit anti-red/green opsin (1:500; Millipore Bioscience Research Reagents; catalog \#AB5405, RRID: AB_177456).

The primary antibodies were diluted with a blocking solution $(1 \%$ NGS, $1 \%$ BSA, and $0.1 \%$ Triton X-100 in PBS) and applied to sections or whole-mounted retinas from overnight to $3 \mathrm{~d}$ at $4^{\circ} \mathrm{C}$. After blocking and rinsing, a secondary antibody conjugated to either Alexa 488 (1:500; Invitrogen; catalog \#A11008, RRID: AB_10563748) or Alexa 568 (1:500; Invitrogen; catalog \#A11077, RRID: AB_2313592) was applied to sections or whole-mounted retinas for $2 \mathrm{~h}$ at room temperature. In doublelabeling experiments using primary antibodies from different hosts, primary antibodies were applied to sections or whole-mounted retinas simultaneously and then visualized by application of appropriate sec- ondary antibodies. Sections and whole-mounted retinas were rinsed and coverslipped in Vectashield mounting medium (Vector Laboratories).

Confocal micrographs of fluorescent specimens from retinal flatmounted preparations and vertical sections were captured using a Zeiss LSM 700 Meta Axioplan 2 laser scanning confocal microscope (Carl Zeiss) equipped with argon and helium-neon lasers. Plan-Apochromat $63 \times / 1.4$ or $40 \times / 1.4$ oil-immersion objectives were used. Image scale was calibrated, and if necessary, brightness and contrast were adjusted using Photoshop CS3 software (Adobe Systems).

Terminal deoxynucleotidyl transferase biotin-dUTP nick end labeling assay. Terminal deoxynucleotidyl transferase biotin-dUTP nick end labeling (TUNEL) assay was conducted for detecting apoptotic photoreceptor cells. In brief, retina sections $(10-12 \mu \mathrm{m}$ in thickness) were digested by proteinase $\mathrm{K}$ at $37^{\circ} \mathrm{C}$ for $30 \mathrm{~min}$, and then reacted with a mixture of terminal deoxynucleotidyl transferase and biotin-dUTP buffer (Millipore) at $37^{\circ} \mathrm{C}$ for $1 \mathrm{~h}$. After terminating the reaction, the biotin-labeled cleavage sites were visualized by reaction with Alexa Fluor 568-conjugated Streptavidin (1:100; Invitrogen) in PBS for $2 \mathrm{~h}$ at room temperature. After several washings with PBS, the slides were mounted in Vectashield mounting medium with DAPI for counter staining nuclei.

Electroretinographic analysis. Electroretinographs (ERGs) were recorded from both minocycline-treated $\mathrm{rd} 10$ mice and age-matched PBStreated $\mathrm{rd} 10$ controls, $\mathrm{rd} 10 / \mathrm{C} \times 3 \mathrm{cr} 1^{+/ G F P}$ mice, and $\mathrm{rd} 10 / \mathrm{C} \times 3 \mathrm{cr} 1^{\mathrm{GFP} / G F P}$ mice, as well as $C \times 3 \mathrm{crl}^{+/ G F P}, C \times 3 \mathrm{cr} 1^{\text {GFP/GFP }}$, and C57BL/6 mice with an Espion ERG Diagnosys machine (Diagnosys). Mice were dark adapted overnight and anesthetized intraperitoneally with a mixture of Dormitor ( $1 \mathrm{mg} / \mathrm{kg}$ medetomidine hydrochloride; Pfizer) and ketamine before the procedures. Pupils were dilated with 1\% Mydriacyl (Alcon). The head of the mouse was held in a standardized position in a Ganzfeld bowl illuminator. Flash ERG was measured using a gold wire corneal electrode, a forehead reference electrode, and a ground electrode near the tail. Scotopic, rod-mediated responses were obtained from dark-adapted animals at the following increasing light intensities: 0.01 and $3 \mathrm{~cd}-\mathrm{s} / \mathrm{m}^{2}$. Photopic, cone-mediated responses were performed following $10 \mathrm{~min}$ light adaptation on the background light intensity of $30 \mathrm{~cd} / \mathrm{m}^{2}$. Recordings were obtained at the light intensity of $3 \mathrm{~cd}-\mathrm{s} / \mathrm{m}^{2}$. Fifteen waveforms from each animal were recorded and the values were averaged. The measurement for the a- and b-waves was done in MATLAB (MathWorks). The ERG a-wave amplitudes were measured from the baseline to the 

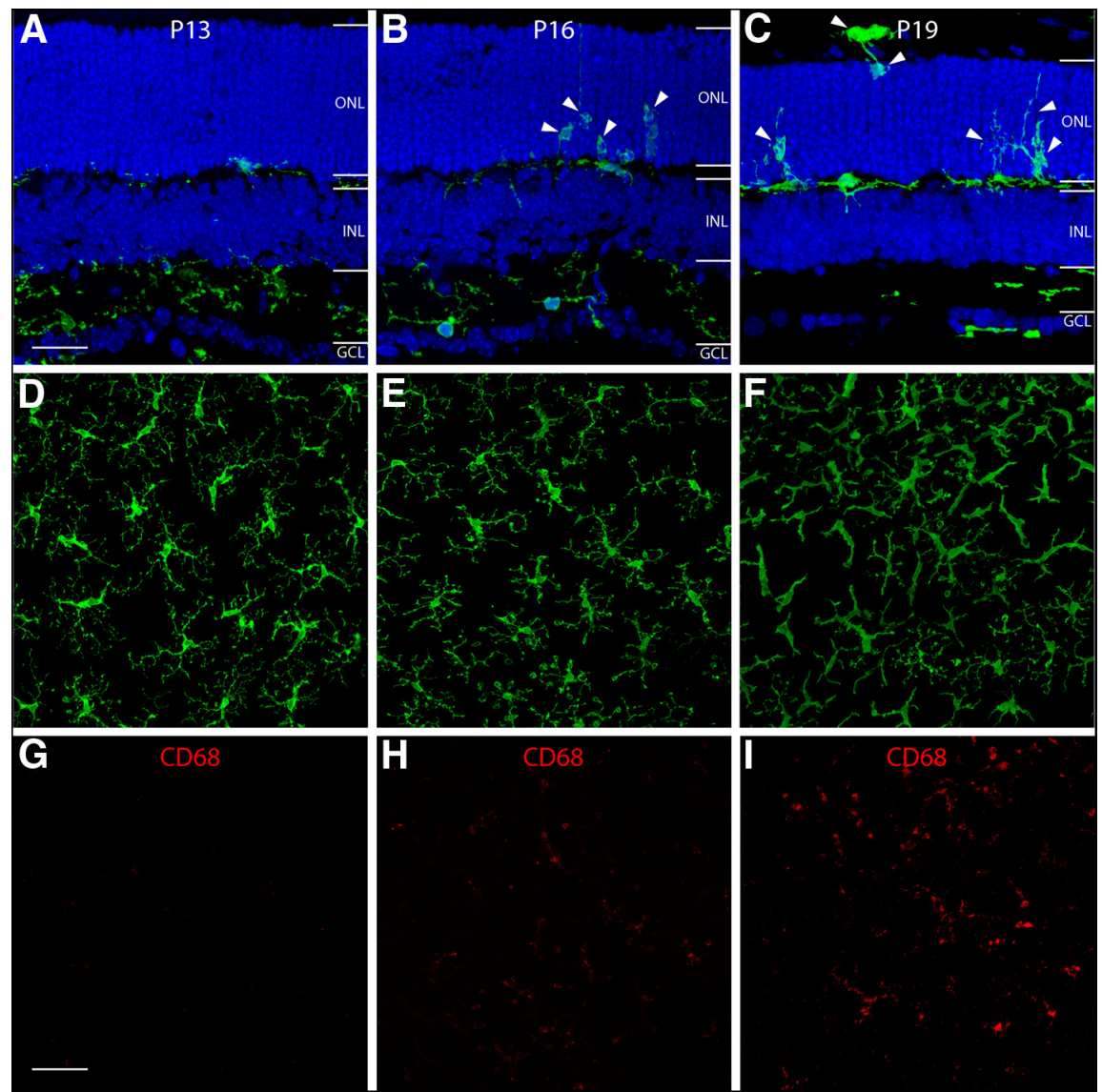

Figure 2. The initiation of microglia activation and migration in rd10 retinas. In retinal sections ( $A-C)$, GFP-expressing microglia are observed to migrate into the inner portion of the ONL at P16 (B, arrowheads), and infiltrate the entire ONL by P19 ( $\boldsymbol{C}$ arrowheads). In retinal whole mounts (D-I), GFP-expressing microglia in the OPL are observed to have a ramified morphology at P13 (D). At P16, microglia begin to change their morphology by retracting their processes $(\boldsymbol{E})$, and turn into an amoeboid shape with few processes by $\mathrm{P} 19(\boldsymbol{F}) . \mathrm{CD} 68$ staining $(\boldsymbol{G}-\boldsymbol{I})$, a marker for microglia activation, first appeared at $\mathrm{P} 16(\boldsymbol{H})$ and became more intense by $\mathrm{P} 19(\boldsymbol{I})$. OPL, outer plexiform layer; IPL, inner plexiform layer; INL, inner nuclear layer; $\mathrm{GCL}$, ganglion cell layer. Scale bars: $A-C, 20 \mu \mathrm{m} ; D-I, 40 \mu \mathrm{m}$.

negative peak and the b-wave was measured from the trough of the a-wave to the peak of the positive wave or, when the a-wave was not present, from baseline to the peak of the first positive wave.

Optokinetic tracking. The methods were adapted from previous studies (Iwakabe et al., 1997; Umino et al., 2008). This test measures the tendency of an animal to follow with the head and eyes against the movement of the surrounding environment. In practice, it was tested by placing the animal on a platform positioned in the middle of an arena created by a quad square of computer monitors. Vertical sine wave gratings $(100 \%$ contrast) written in MATLAB were projected on the computer monitors. The spatial frequencies tested were $0.05,0.075,0.1,0.2$, $0.3,0.4,0.5$, and 0.6 cycles per degree, at a constant speed of 12 degrees/s. The image of eye movements was monitored by an infrared-sensitive small camera.

Flow cytometry. Twenty-four hours after the final intraperitoneal injection of minocycline or PBS, rd10 mice were anesthetized. Eyes were rapidly removed, and retinas were dissected in an oxygenated Ames' solution (Sigma-Aldrich). Retinas from seven mice in each group were pooled together and minced, and then trypsinized for $30 \mathrm{~min}$ at $37^{\circ} \mathrm{C}$. After quenching and fixation, the cells were incubated with fluorescently conjugated CD11b (1:250; BD PharMingen; catalog \#557396, RRID: AB_396679) and CD45 antibodies (1:250; BD PharMingen; catalog \#559864, RRID: AB_398672) in FACS buffer on ice for $2 \mathrm{~h}$. Fluorescently labeled cell populations were separated using a BectonDickinson FACSAria I Flow Sorter. Activated microglia were defined as CD11b-positive/CD45-high, whereas resting microglia were CD11b-positive/CD45-low.
ELISA measurement. ELISA for tumor necrosis factor- $\alpha$ (TNF- $\alpha$ ), COX-1, COX-2, caspase-3/7 and Bax levels in retinas were quantified using ELISA kits from PeproTech, Cell Signaling Technology, and EIAab, respectively, according to manufacturer's instructions as previously described (Xiao et al., 2013).

Data analysis. For measurement of outer nuclear layer (ONL) thickness at P25, only vertical sections passing through the optic nerve head were analyzed by counting the number of photoreceptor nuclei in the ONL. Three vertical sections per eye were analyzed and measurements were taken at $200 \mu \mathrm{m}$ (central region) and $1 \mathrm{~mm}$ (mid-peripheral region) from the optic nerve on both sides. Quantification of activated microglia was conducted in retinal whole mounts, using a $40 \times$ objective (NA 0.85). Sampling areas were four $240 \times 240$ $\mu \mathrm{m}$ squares along the dorsoventral axis of retinal whole mounts per retina, at $200 \mu \mathrm{m}$ (central region) and $1 \mathrm{~mm}$ (mid-peripheral region) from the optic nerve on both sides.

Statistical analyses. All data were expressed as mean $\pm \mathrm{SD}$. ANOVAs with Bonferroni's and Dunnett's post hoc tests for multiple comparisons were performed with Origin (Origin$\mathrm{Lab})$ and programs written in MATLAB (MathWorks) on full datasets to detect significant differences in the mean. A $p$ value $<0.05$ was considered statistically significant.

\section{Results}

Association of microglia activation with photoreceptor apoptosis in rd10 retinas To identify the initiation of photoreceptor cell apoptosis in rd10 retinas, we performed TUNEL assay on retinal sections. No TUNEL-positive photoreceptor nuclei were observed in rd10 retinas at $\mathrm{P} 16$ (Fig. 1A,D). TUNEL-positive photoreceptor nuclei were initially detected in the ONL of the rd10 retina at P19 (Fig. $1 B, E$, arrows). At P22, TUNEL-positive photoreceptor nuclei were detectable at all levels of the ONL (arrows, Fig. 1C,F). On P30, only scattered TUNEL-positive photoreceptor cells were observed. In contrast, no TUNEL-positive photoreceptor nuclei were detected in WT mouse retinas (data not shown).

During CNS inflammation, microglial cells are activated and contribute to the pathological processes. To visualize and characterize early microglia activation in $\mathrm{rd} 10$ retinas, we bred $\mathrm{rd} 10$ mice with $C \times 3 \mathrm{cr} 1^{G F P / G F P}$ mice. Retinal sections and whole-mounted retinas from WT $C \times 3 c r 1^{+/ G F P}$ mice and $\mathrm{rd} 10 / C \times 3 \mathrm{cr} 1^{+/ G F P}$ mice were analyzed for GFP fluorescence. Microglia in WT $C \times 3 c r 1^{+/ G F P}$ mouse retinas were exclusively localized in the inner and outer plexiform layers and ganglion cell layer. The number and distribution of microglia in the $\mathrm{rd} 10 / \mathrm{C} \times 3 \mathrm{cr} 1^{+/ G F P}$ retina were comparable to those in the control WT $C \times 3 c r 1^{+/ G F P}$ retinas at P13 (Fig. $2 A)$. From P16 onward, activated microglia/macrophage were observed to migrate into the inner portion of the ONL (Fig. 2B, arrowheads), with an increasing microglia infiltration into the entire ONL by P19 (Fig. 2C, arrowheads). To confirm the presence of microglia activation, we performed CD68 staining, a marker for microglia activation, to label these activated microglia in whole-mounted retinas of $\mathrm{rd} 10 / \mathrm{C} \times 3 \mathrm{cr} 1^{+/ G F P}$ mice (Fig. $2 D-I$ ). CD68 staining initially appeared at P16 (Fig. $2 \mathrm{H}$ ), and became 
intense by P19 (Fig. 2I). Microglia took on a ramified appearance at P13 (Fig. $2 A, D)$. Then, microglia gradually underwent a morphological change into an amoeboid shape with retracted processes and increasing age (Fig. 2C,F).

Together, the retinal microglia were activated and infiltrated the ONL at P16 (Fig. $2 \mathrm{~B}, \mathrm{H}$ ), whereas photoreceptor apoptosis started at P19 (Fig. $1 B, E$ ), indicating that microglia activation preceded the initiation of photoreceptor apoptosis. Our results were consistent with several previous studies (Zeiss and Johnson, 2004; Zeng et al., 2005; Gehrig et al., 2007), indicating that microglia activation was an early alteration in the rd10 retina and might potentially contribute to disease progression.

\section{Minocycline treatment inhibits microglia activation in rd10 retinas}

To confirm the involvement of microglia in photoreceptor apoptosis, we administered minocycline into rd10 mice to suppress microglia activation. Minocycline, which effectively crosses the blood-brain barrier, has been reported to be an inhibitor of microglial activation in the brain and retina (Wu et al., 2002; Shen et al., 2011). Minocycline administration started from P13, right before the initiation of microglia activation, and continued until the animals were killed. Control rd10 animals received injections of PBS on the same schedule. The majority of photoreceptors are degenerated by P25 in the rd 10 retina (Gargini et al., 2007). Thus, we chose P25 as the end point to examine the preservation of photoreceptor structure and function in rd10 mice following $12 \mathrm{~d}$ (P13 to P24) of minocycline treatment. At P25, we found less intense CD68 immunoreactivity in minocycline-treated $\mathrm{rd10} / \mathrm{C} \times 3 \mathrm{cr} 1^{+/ G F P}$ retinas (Fig. $3 B$ ) when compared with PBS-treated $\mathrm{rd10} / \mathrm{C} \times 3 \mathrm{cr} 1^{+/ G F P}$ mice (Fig. $3 E$ ). Microglia in minocycline-treated $\mathrm{rd} 10 / \mathrm{C} \times 3 \mathrm{cr} 1^{+/ G F P}$ retinas maintained a ramified appearance at P25 (Fig. 3A), while a substantial number of activated amoeboid microglial cells with retracted processes and rounded cell bodies were observed in the ONL of PBS-treated $\mathrm{rd} 10 / \mathrm{C} \times 3 \mathrm{cr} 1^{+/ G F P}$ retinas (Fig. 3D, arrowheads). The percentage of CD68-positive microglia over total microglial cells was significantly different between the two groups ( $15.0 \pm 2.6 \%$ following minocycline treatment vs $94.1 \pm 8.7 \%$ in PBS-treated controls, $p<0.01$; Fig. $3 G$ ). In addition, we observed fewer number of microglia infiltration to the ONL compared with PBS-treated $\mathrm{rd} 10 / \mathrm{C} \times 3 \mathrm{cr} 1^{+/ G F P}$ retinas at both P16 and P19 (Fig. $3 H$ ). Therefore, our data suggested that minocycline treatment significantly reduced microglial activation in $\mathrm{rd} 10$ retinas.

Resting microglia expressed CD11b and a low level of CD45 $\left(\mathrm{CD} 45^{\mathrm{lo}}\right)$ when compared with those activated microglia, which expressed CD11b-positive and CD45-high (CD45 $\left.{ }^{\text {hi }}\right)$. Activated and resting microglia can thus be separated by two-color flow cytometry based on relative levels of CD45 expression (Fig. 4A$C)$. Flow cytometry analysis of the expression of CD45 confirmed that the percentage of CD $45^{\text {hi }}$ microglia over total retinal cells
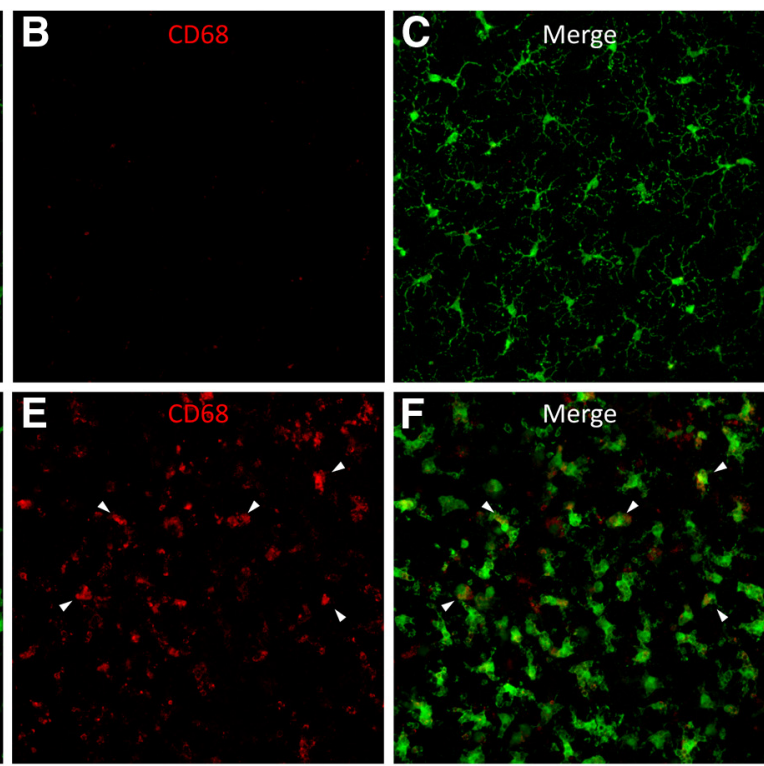

H

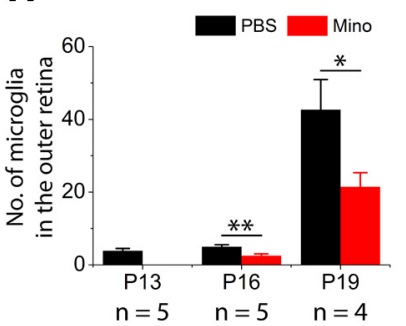

$n=4$

$\mathrm{n}=5 \quad \mathrm{n}=5 \quad \mathrm{n}=4$

Figure 3. Minocycline treatment reduces microglia activation and infiltration in rd10 retinas. $\boldsymbol{A}-\boldsymbol{C}$, At P25, microglia maintain widespread (E) G The percentage of CD68-positive microglia over total microglial cells. $\boldsymbol{H}$, Quantification of microglial cells that migrated into the outer retina in PBS-treated and minocycline-treated animals at three time points before P25. Results are presented as mean $\pm S D_{;}^{*} p<0.05,{ }^{* *} p<0.01, n=$ number of retinas in each group. Scale bar, $20 \mu \mathrm{m}$.

was significantly lower in minocycline-treated rd10 mice than in PBS-treated rd10 mice $(0.307 \pm 0.005 \%$ following minocyclinetreatment vs $0.693 \pm 0.043 \%$ in controls, $p<0.01$; Fig. $4 D$ ) suggesting that minocycline treatment suppressed microglial activation.

\section{Minocycline treatment attenuates photoreceptor degeneration}

We investigated whether the inhibition of microglia activation could slow down photoreceptor degeneration in rd10 retinas. We observed that administration of minocycline delayed the onset of photoreceptor apoptosis. No apoptotic photoreceptors were detected in the ONL by P19 (Fig. $5 A, D, B, E$ ), the time when apoptotic photoreceptors initially appeared in PBS-treated rd10 retinas (Figs. $1 B, E, 5 G$ ). Compared with rd10 controls at $\mathrm{P} 22$ (Fig. 1C,F), the extent of photoreceptor apoptosis in the ONL was substantially reduced in minocycline-treated $\mathrm{rd} 10$ retinas (Fig. 5C,F), suggesting that minocycline treatment reduced photoreceptor apoptosis.

The measurement of ONL thickness confirmed the results obtained from TUNEL staining. Following minocycline treatment from P13 to P24, the numbers of photoreceptor nuclei in the ONL were counted in vertical sections at P25. Photoreceptor degeneration in $\mathrm{rd} 10$ retina started from the central-toperipheral region. The study of rod and cone cell death thus required observation in the same region of the retina between 


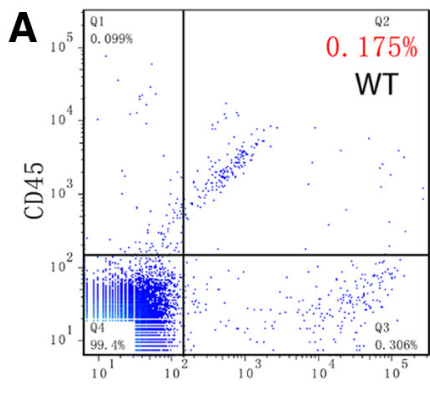

CD11b

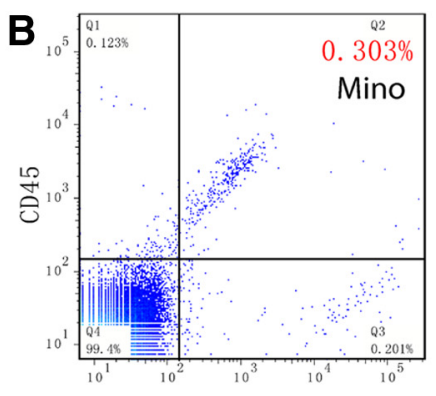

CD11b
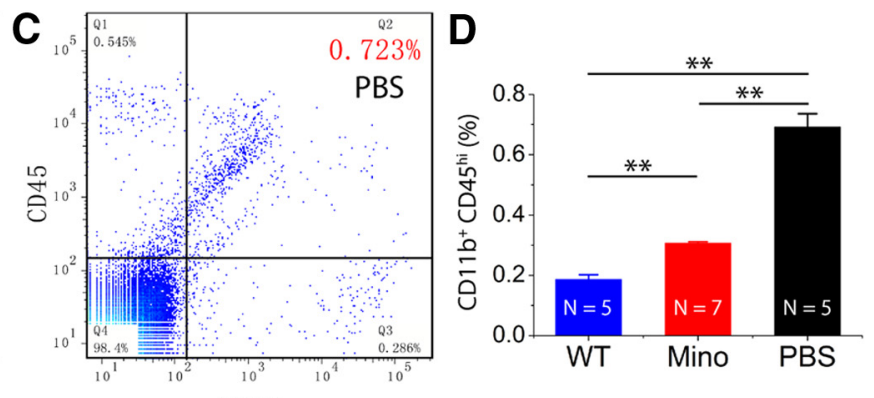

Figure 4. Quantification of activated microglial cells by flow cytometry analysis. A-C, Microglia analyzed by two-color flow cytometry displayed different patterns of CD11b and CD45 expression in rd10 retinas treated with minocycline (Mino) treatment $(\boldsymbol{B})$ and PBS (C). Retinas from WT mice at the same age are used as a comparison (A). CD45 expression is shown on the $y$-axis and CD11b expression is shown on the $x$-axis. Region 2 shows the percentage of the subpopulation of $C D 11 b^{+}{ }^{+} D 45^{\text {hi }}$-activated microglia/macrophages. $D$, The percentages of activated microglia/macrophages over total retinal cells were quantified. Mean $\pm S D ;{ }^{* *} p<0.01$.
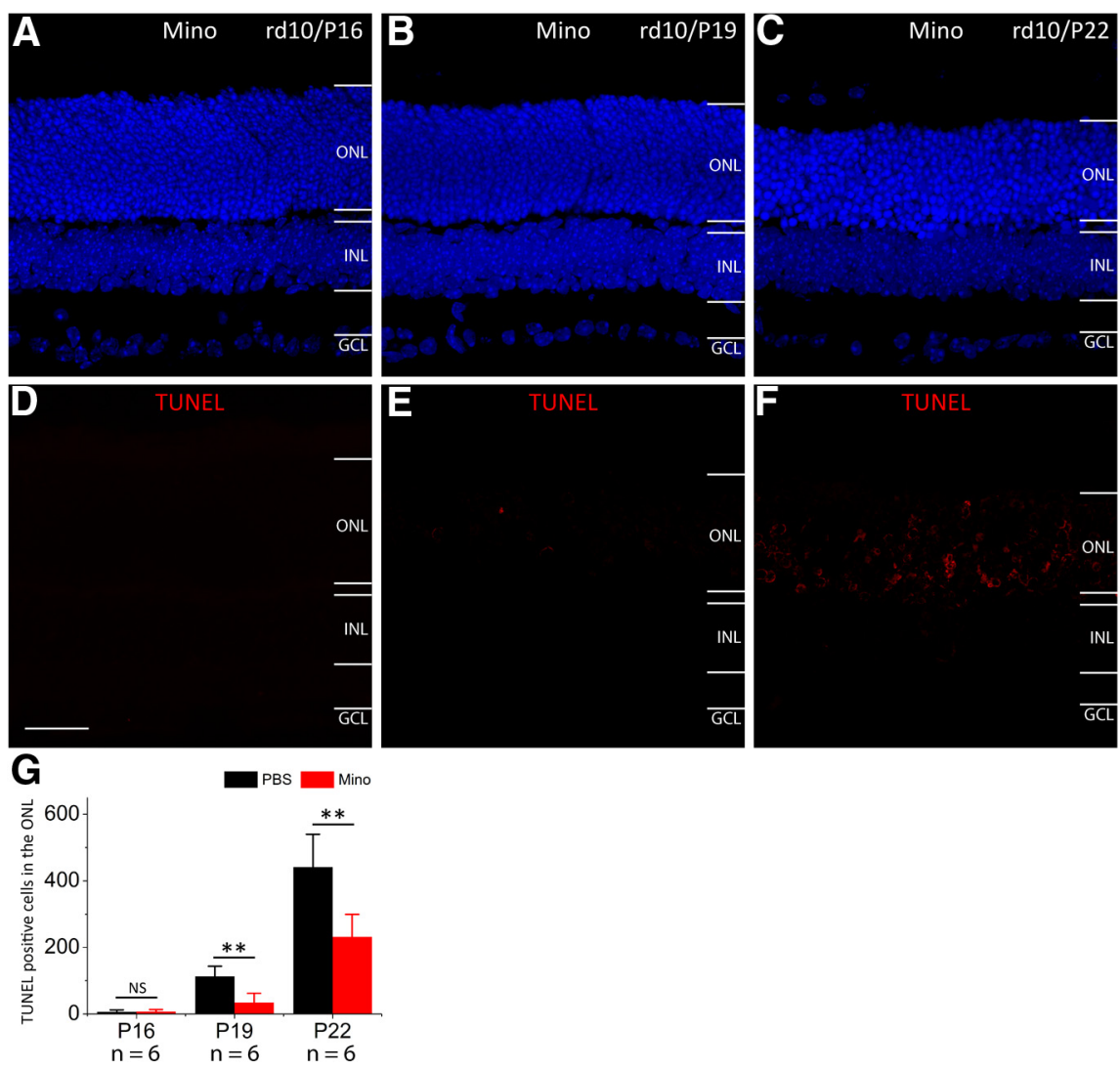

Figure 5. Minocycline (Mino) treatment reduces photoreceptor apoptosis. The nuclear layers were stained with DAPI (A-C blue). No TUNEL-positive photoreceptor cells (red) are observed in the ONL at both P16 (D) and P19 (E). TUNEL-positive photoreceptor cells begin to appear in the ONL at P22 (F). G, Quantification of TUNEL-positive photoreceptor cells in the ONL at three time points. Note that the number of TUNEL-positive photoreceptor cells significantly decreased in minocycline-treated rd10 mice at P19 and P22. Results are presented as mean \pm SD; ${ }^{* *} p<0.01, n=$ number of retinas in each group. OPL, outer plexiform layer; INL, inner nuclear layer; IPL, inner plexiform layer; $\mathrm{GCL}$, ganglion cell layer. Scale bar, $20 \mu \mathrm{m}$.

groups. The regions in the superior retina that were located at 200 $\mu \mathrm{m}$ from the ONL were targeted for measurements (Fig. 6A-C). Rd10 mice treated with minocycline had a significantly thicker photoreceptor nuclear layer $(10.3 \pm 2.4$ rows, $n=7$ retinas; Fig. $6 D$, red bar) when compared with the control rd10 eyes injected with PBS $(5.9 \pm 1.1$ rows, $n=5$ retinas; $p<0.01$; Fig. $6 D$, black bar). A similar phenomenon was observed in the peripheral retina (data not shown). The ONL thickness from WT C57BL/6 retinas $(17.0 \pm 3.2$ rows, $n=5$ retinas; Fig. $6 D$, blue bar $)$ was also measured for comparison. These results showed that minocy- cline treatment provided a significant morphological preservation of rods throughout the retina. In normal WT C57BL/6 mice, administration of minocycline did not affect ONL thickness (data not shown).

In addition to the preservation of rods, we also observed relatively preservation of cone inner and outer segments in minocycline-treated $\mathrm{rd} 10$ retinas. To better characterize this protective effect on cones, we stained vertical sections with anti-red/green opsin antibody. At the age of $25 \mathrm{~d}$, cones in the rd10 retina showed disrupted inner segments (ISs)/outer segments (OSs), which were not like the WT (Fig. 6E,H). Although the length of the OS/IS was shorter than that in the WT C57BL/6 mice $(p<0.01$; Fig. $6 E, H, K)$, it was significantly longer than that in the saline-injected controls $(p<0.01$; Fig. $6 G, J, K)$. Therefore, minocycline preserved both rods and cone morphology in rd10 retinas.

\section{Minocycline treatment preserves photoreceptor function}

To assess whether minocycline treatment preserved photoreceptor cell function and visual behavior in rd10 mice, we performed functional studies by measuring scotopic and photopic ERGs and optomotor responses at P25. Retinal function in minocycline-treated rd10 eyes was markedly better preserved with larger scotopic and photopic ERG responses than in the PBS-treated rd10 eyes at P25 (Fig. 7). Minocycline treatment partially prevented the reduction in scotopic ERG a-wave amplitudes when compared with PBS-treated rd10 controls at two light intensities $(p<0.01$; Fig. $7 A, B, D, E)$. Compared with those treated with PBS, $r d 10$ mice treated with minocycline also had greater mean amplitude of b-wave $(p<0.01$; Fig. $7 A, B, D, E)$. A similar trend was also observed for average latency time (time to peak). The latency time for scotopic ERG a- and b-waves in minocycline-treated $\mathrm{rd} 10$ mice was significantly shorter than in PBS-injected rd10 controls $(p<0.01$; Fig. 7G, $H)$. 

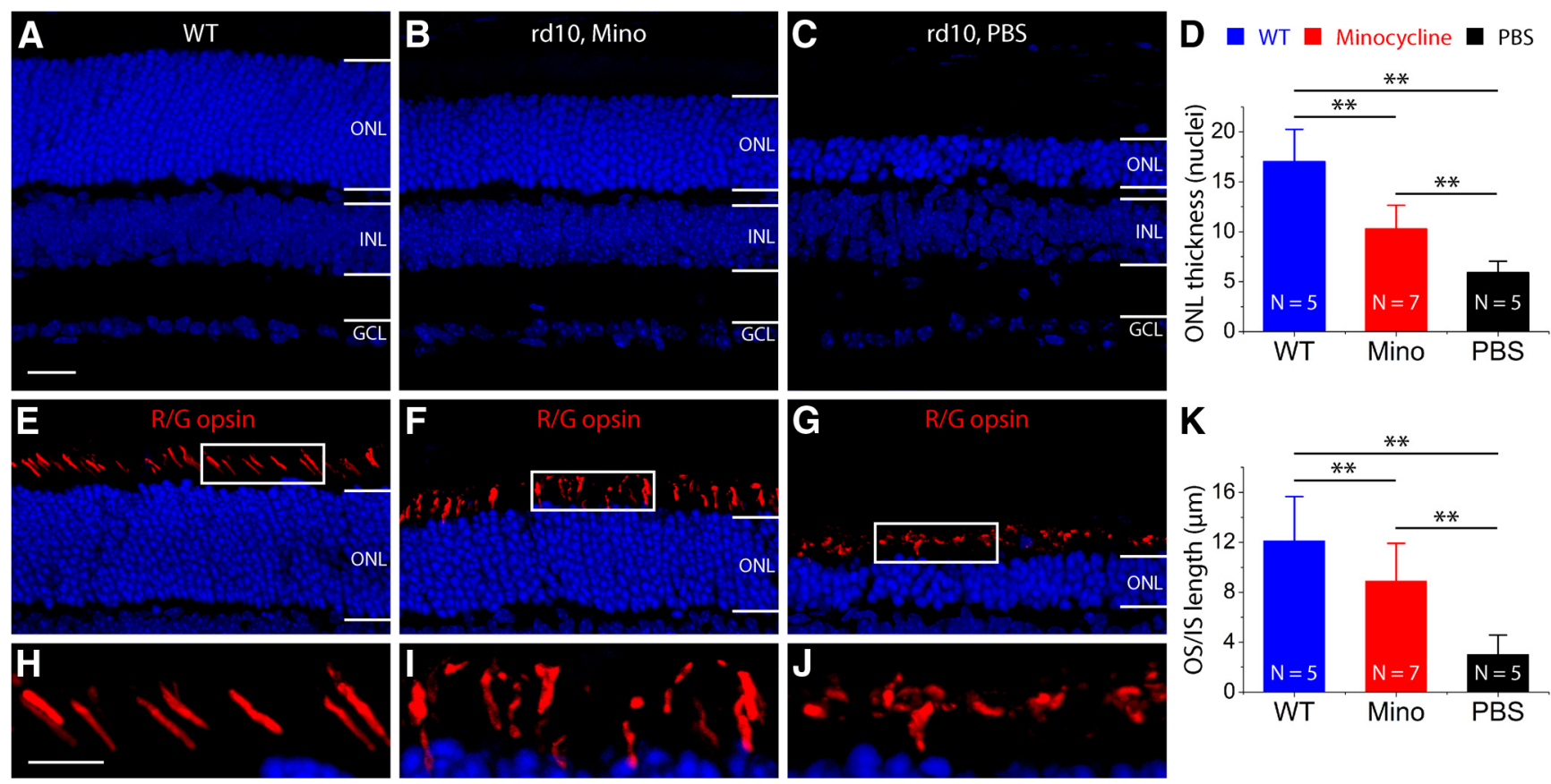

Figure 6. Morphological preservation of photoreceptors by minocycline (Mino) treatment. $\boldsymbol{A}-\boldsymbol{C}$, The thickness of the ONL in rd10 retinas is protected by minocycline treatment $(\boldsymbol{B})$ from progressive thinning as observed in the PBS-treated rd10 retina due to rod cell death (C). Retinas from WT mice at the same age are used as a comparison $(\boldsymbol{A})$. D, Plot of the thickness of the ONL, measured in numbers of photoreceptor nuclei per column. Results are presented as means $\pm S D ; n=$ number of retinas in each group, ${ }^{* *} p<0.01$. $E-J$, The $0 S s / L S$ of cone photoreceptors revealed by red/green opsins. In WT retinas, only OSs were positive for red/green opsins (R/G opsin; $\boldsymbol{E}, \boldsymbol{H})$. In rd10 retinas, OSs/SSs were disrupted. The $0 S / / S$ s of cone photoreceptors in minocycline-treated rd10 mice $(\boldsymbol{F}, \boldsymbol{I})$ look better than those in PBS-treated rd10 mice $(\boldsymbol{G}, J) . \boldsymbol{K}$, Plot of the length of $0 \mathrm{Ss} / \mathrm{ISs}$. Results are presented as means \pm SD; $n=$ number of retinas in each group, ${ }^{* *} p<0.01$. INL, inner nuclear layer; $\mathrm{GCL}$, ganglion cell layer. Scale bars: $A-G, 20 \mu \mathrm{m} ; \boldsymbol{H}-J, 10 \mu \mathrm{m}$.

The scotopic ERG results indicated that minocycline provided significant preservation of rod function.

Photopic ERG a-wave amplitudes were also preserved in minocycline-treated $\operatorname{rd} 10$ animals $(-9.82 \pm 1.07 \mu \mathrm{V}$ in minocycline-treated rd10 group vs $-5.55 \pm 1.37 \mu \mathrm{V}$ in PBStreated rd10 group; $p<0.05$; Fig. $7 C, F$ ), while photopic b-waves did not differ significantly between minocycline-treated and saline-injected rd10 animals $(66.54 \pm 4.59 \mu \mathrm{V}$ in minocyclinetreated $\operatorname{rd} 10$ group vs $57.58 \pm 6.11 \mu \mathrm{V}$ in PBS-treated $\mathrm{rd} 10$ group; $p>0.05$; Fig. $7 C, F$ ). The average latency time for either photopic ERG a-waves or photopic ERG b-waves did not differ in the two groups ( $p>0.05$; Fig. $7 I)$. The photopic ERG results indicated that cone function of rd10 mice was significantly preserved by minocycline. While a significant functional improvement was observed in minocycline-treated rd10 animals, the scotopic and photopic ERGs were still substantially reduced when compared with WT mouse eyes (Fig. 7, blue curves and bars). These results indicated that minocycline exerted a partial protective effect and did not fully arrest the course of disease.

By $30 \mathrm{~d}$ of age, the protective effect of minocycline on conederived retinal function became prominent. Although darkadapted a-waves became undetectable in two groups of animals, light-adapted responses differed significantly between minocyclineand saline-injected $\operatorname{rd} 10$ groups $(42.41 \pm 5.70 \mu \mathrm{V}$ in minocycline-treated rd10 group vs $25.06 \pm 3.98 \mu \mathrm{V}$ in PBStreated $\operatorname{rd} 10$ group; $p<0.05$; data not shown). However, average latency time for photopic ERG b-waves was similar in the two groups ( $p>0.05$; data not shown).

To evaluate visual acuities in minocycline-treated $\mathrm{rd} 10$ mice, we measured the optokinetic response to moving gratings of different spatial frequencies at $100 \%$ contrast. The optokinetic response is an established simple and precise method for quanti- fying mouse vision (Prusky et al., 2004). Optokinetic behavioral analysis showed that light-adapted visual acuity in minocyclinetreated $\operatorname{rd} 10$ mice (red bar, $n=13$ ) was significantly better than that of PBS-treated rd10 eyes ( $n=9, p<0.05$; Fig. 7J, black bar), but was smaller than that in the WT mouse eyes $(n=7, p<0.01$; Fig. 7J, blue bar).

Our data demonstrated that minocycline treatment preserved the morphology and function of photoreceptors in rd10 retinas, suggesting that the activation of microglia/macrophages was a major contributing factor to the pathology of retinal degeneration.

\section{Minocycline treatment downregulates pro-inflammatory mediators and apoptosis}

To understand the mechanism underlying the beneficial effects of minocycline treatment, we determined the protein levels of proinflammatory mediators produced by activated microglia using ELISA. Since most of experimental end points were on P25, we evaluated protein expression levels of pro-inflammatory mediators at this time point.

At P25, retinal protein levels of pro-inflammatory cytokine, TNF- $\alpha$, and COX- 1 and COX-2 were significantly elevated in saline-injected rd10 mice when compared with WT controls (Fig. $8 A-C$, black bars). Following minocycline treatment, we observed a significant reduction in protein levels of TNF- $\alpha$, COX-1, and COX-2 (Fig. $8 A-C$, red bars), indicating that minocycline treatment reduced pro-inflammatory molecule expressions.

At $25 \mathrm{~d}$ of age, the protein levels of the Bcl-2 family Bax and caspase-3/7 in rd10 retinas were significantly higher when compared with WT controls (Fig. $8 D$, E, black bars). Following $12 \mathrm{~d}$ of minocycline treatment, we found that retinal protein levels of Bax and caspase- $3 / 7$ were significantly reduced compared with PBStreated rd10 mice (Fig. $8 D, E$, red bars). These data suggested that 

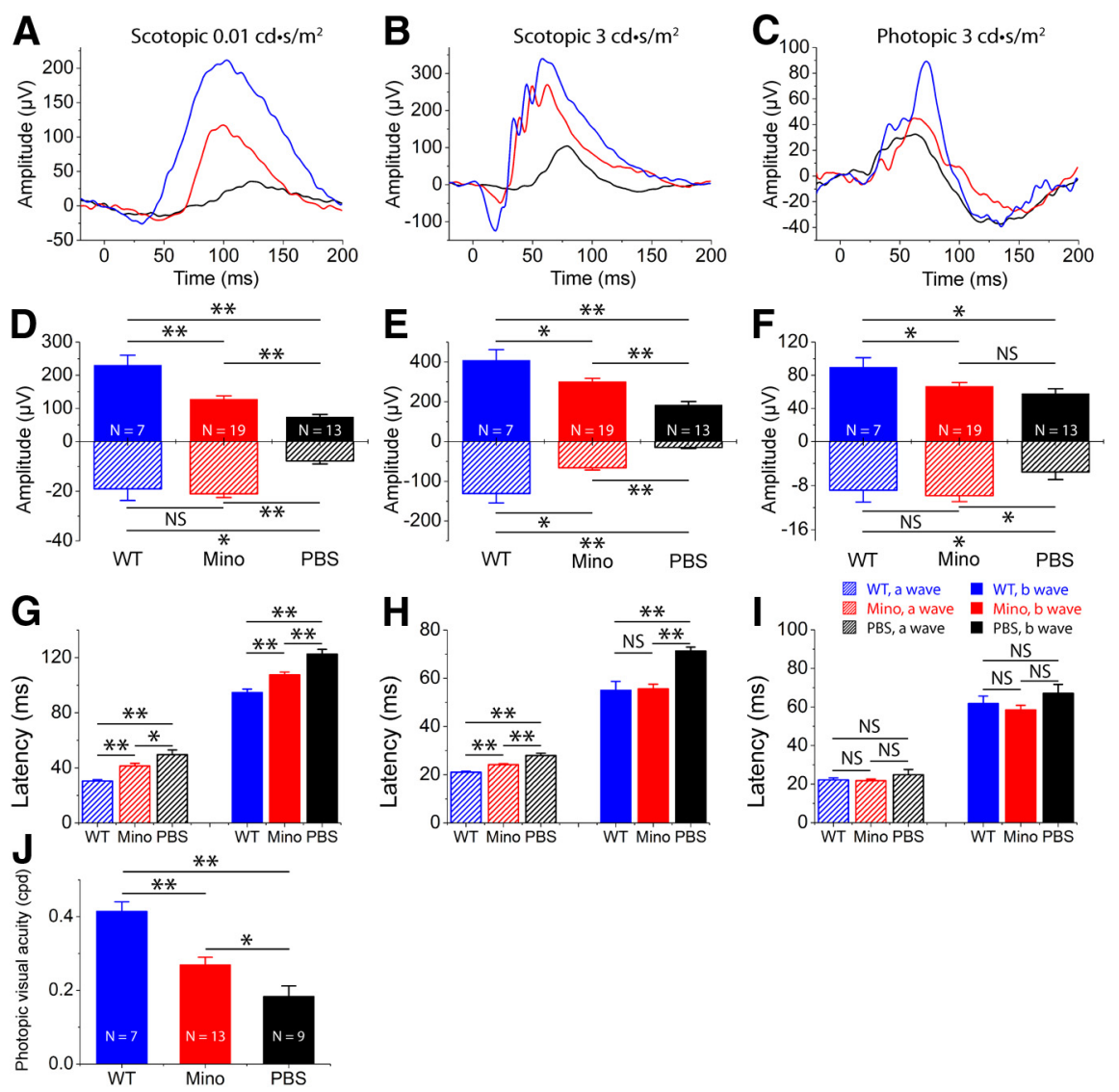

Figure 7. Functional preservation of photoreceptors by minocycline (Mino) treatment. $\boldsymbol{A}, \boldsymbol{B}$, Representative scotopic ERG responses to 0.01 and $3 \mathrm{~cd}-\mathrm{s} / \mathrm{m}^{2}$ light intensities from rd 10 mice at P25 treated with minocycline (red curve) or PBS (dark curve) from P13 to P24. Scotopic ERG responses from C57BL/6 (blue curve) are shown as comparisons. D, E, Average scotopic a-wave and b-wave amplitudes elicited at $0.01 \mathrm{~cd}-\mathrm{s} / \mathrm{m}^{2}(\boldsymbol{D})$ and $3 \mathrm{~cd}-\mathrm{s} / \mathrm{m}^{2}(\boldsymbol{E})$ light intensities from normal $\mathrm{C57} \mathrm{BL} / 6$ (blue), minocyclinetreated (red), and PBS-treated (dark) rd10 eyes. Data are expressed as the mean \pm SD. C, Representative photopic ERGs elicited at $3 \mathrm{~cd}-\mathrm{s} / \mathrm{m}^{2}$ light intensity from the same three groups of mice as scotopic recording. $\boldsymbol{F}$, Averaged photopic a-wave and b-wave amplitudes elicited at $3 \mathrm{~cd}-\mathrm{s} / \mathrm{m}^{2}$ light intensity from normal $\mathrm{C} 57 \mathrm{BL} / 6$ (blue), minocycline-treated (red), and PBS-treated (dark) rd10 eyes. G-I, Average latency time (time to peak) for scotopic ERG a-waves and b-waves at $0.01 \mathrm{~cd}-\mathrm{s} / \mathrm{m}^{2}(\boldsymbol{G})$ and $3 \mathrm{~cd}-\mathrm{s} / \mathrm{m}^{2}(\boldsymbol{H})$ light intensities, and for photopic ERG a-waves and b-waves at $3 \mathrm{~cd}-\mathrm{s} / \mathrm{m}^{2}(I) . J$, Photopic visual acuity measured by the optokinetic response. Values are means and SDs. $n=$ animal numbers; ${ }^{*} p<0.05$ and ${ }^{* *} p<0.01$.

the protective effects of minocycline were mediated through its anti-inflammatory and anti-apoptotic properties, leading to preservation of structure and function of photoreceptors in $\mathrm{rd} 10$ mice.

\section{COX inhibition provides significant protection of photoreceptor function}

Minocycline has been shown to reduce microglial activation and improve neuronal survival in different models of neurodegenerative disease (Yrjänheikki et al., 1998; Yong et al., 2004; Zhang et al., 2004; Fan et al., 2007; Lazarini et al., 2012; Schafer et al., 2012). We observed the same phenomenon in rd10 retinas. Additionally, we found that minocycline could directly exert its neuroprotective effects. To further confirm that the suppression of microglial activation was neuroprotective in $\mathrm{rd} 10$ retinas, we applied the COX-1-specific inhibitor SC-560 to suppress microglia activation (Choi et al., 2008; García-Bueno et al., 2009; Griffin et al., 2013). Because of its predominant expression in microglia, COX-1 facilitates activation of microglia and supports neuroinflammatory processes in several models of neurodegenerative disorders (García-Bueno et al., 2009; Griffin et al., 2013). We found that SC-560 significantly reduced the expression of pro- inflammatory cytokine TNF- $\alpha$ in $\operatorname{rd} 10$ retinas when compared with vehicletreated rd10 mice (Fig. $8 F$ ). Interestingly, we found that SC-560 slightly downregulated the expression of COX-2 protein (Fig. $8 G ; p>0.05$ ). Meanwhile, the expression levels of BAX and caspase-3/7 were also reduced in SC-560-treated rd10 mice compared with vehicle-treated rd10 mice (Fig. $8 H, I$ ). Quantification of the number of photoreceptor nuclei within the ONL showed that the photoreceptors in SC-560-treated rd10 retinas were significantly preserved (Fig. 8J; $p<$ $0.05)$. Therefore, suppression of microglia activation by SC-560 reduced the production of microglia-derived pro-inflammatory factors, leading to the preservation of photoreceptors and subsequent reduction of BAX and caspase- $3 / 7$ production.

\section{Effect of $C x 3 c r 1$ on microglial activation in $\mathrm{rd} 10$ retinas}

In the CNS, fractalkine $(\mathrm{Cx} 3 \mathrm{cll})$ is primarily expressed by neurons, whereas its unique G-protein-coupled receptor $(\mathrm{C} \times 3 \mathrm{cr} 1)$ is specifically expressed by microglia. It has been suggested that $\mathrm{Cx} 3 \mathrm{cl} 1$ is important for microglial regulation and communication between microglia and neurons (Cardona et al., 2006). We thus investigated whether $C \times 3 c r 1$ receptor was involved in regulating microglia activation in rd10 retinas. Previous studies have shown that retinas do not exhibit structural differences in retinal lamination or overall morphology and distribution of microglia in the absence of $C \times 3 c r 1$ signaling in early adulthood (Liang et al., 2009). Our ERG measurements confirmed the morphological analysis. We showed that scotopic and photopic ERG responses were indistinguishable between $C \times 3 c r 1^{G F P / G F P}$ mice and $C \times 3 c r 1^{+/ G F P}$ mice (Fig. 9, blue curves and bars), suggesting $C \times 3 c r 1$ deletion did not affect retinal structure and function during retina development.

We then studied whether $C x 3 \mathrm{cr} 1$ deficiency affected microglia response in rd10 retinas. To this end, we backcrossed $\mathrm{C} \times 3 \mathrm{cr} 1$ knock-out mice ( $\left.\mathrm{C} \times 3 \mathrm{cr} 1^{G F P / G F P}\right)$ into rd10 background and generated a new line of $\mathrm{rd10/Cx3} 3 \mathrm{cr}^{\text {GFP/GFP }}$ mice. At P25, scotopic and photopic ERG a-wave amplitudes were virtually indistinguishable between $\mathrm{rd} 10 / C \times 3 \mathrm{cr} 1^{+/ G F P}$ and $\mathrm{rd10/C} \times 3 \mathrm{cr} 1^{\text {GFP/GFP }}$ mice ( $p>0.05$; Fig. 9 , black curves and bars), indicating the similar level of loss of functional rods in rd10 mice with or without $\mathrm{Cx} 3 \mathrm{cr} 1$ at P25. However, scotopic and photopic ERG b-wave amplitudes were significantly smaller in $\mathrm{rd} 10 / C \times 3 \mathrm{cr} 1^{\text {GFP/GFP }}$ mice than in $\mathrm{rd10/C \times 3} \mathrm{cr}^{+/ G F P}$ mice (Fig. 9, black curves and bars), indicating that $C \times 3 \mathrm{cr} 1$ deficiency exaggerated cone photoreceptor degeneration in rd10 mice.

To correlate ERG results with morphological changes, we then counted the number of ONL rows. There was a significant difference in the ONL thickness between $\mathrm{rd} 10 / \mathrm{C} \times 3 \mathrm{cr} 1^{+/ G F P}$ and $\mathrm{rd} 10 /$ $C \times 3 \mathrm{cr} 1^{G F P / G F P}$ mice at $\mathrm{P} 25\left(5.8 \pm 1.2\right.$ rows in $\mathrm{rd} 10 / \mathrm{C} \times 3 \mathrm{cr} 1^{+/ G F P}$ group vs $4.2 \pm 1.0$ rows in $\mathrm{rd} 10 / C \times 3 c r 1^{\text {GFP/GFP }}$ group; $n=10 ; p<$ 

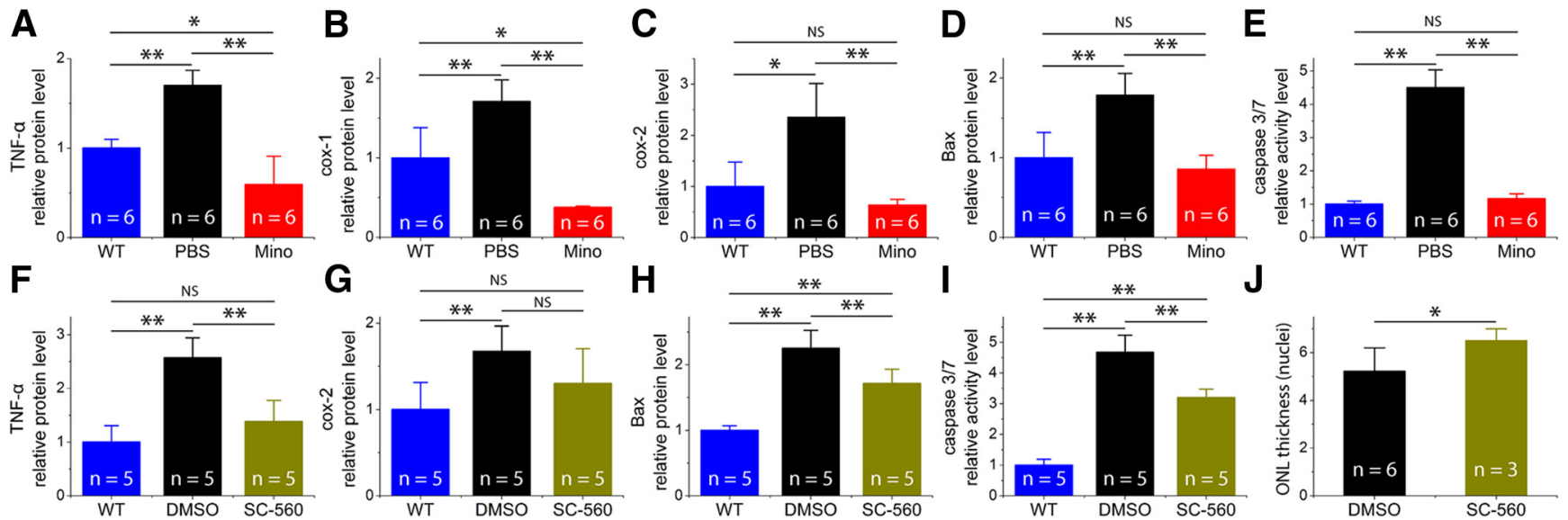

Figure 8. Downregulation of pro-inflammatory cytokines and pro-apoptotic molecules by minocycline (Mino) treatment or by COX-1-specific inhibitor SC-560. The protein levels of these molecules were assessed using ELISA. $\boldsymbol{A}-\boldsymbol{E}$, Results from minocycline treatment. Pro-inflammatory cytokine TNF- $\alpha(\boldsymbol{A})$, COX-1 (B), and COX-2 (C) are upregulated in rd10 retinas (black bars) and downregulated following minocycline treatment (red bars). The similar trends were observed for pro-apoptotic molecules Bax (D) and caspase-3/7 (E). $\boldsymbol{F}-\boldsymbol{J}$, Results from SC-560 treatment. Pro-inflammatory cytokines TNF- $\alpha(\boldsymbol{F})$ and COX-2 (B) are downregulated following SC-560 treatment. The similar trends are observed in Bax $(\boldsymbol{H})$ and caspase-3/7 $(\boldsymbol{I})$. $\boldsymbol{J}$, Plot of the thickness of the ONL, measured in numbers of photoreceptor nuclei per column. Results are presented as means \pm SD; $n=$ number of retinas in each group, ${ }^{*} p<0.05$.

0.05; Fig. $10 A, C, F)$. In addition, the significant difference in the ONL thickness was detected at P19 as well $(17.3 \pm 2.1$ rows in $\mathrm{rd} 10 / \mathrm{C} 3 \mathrm{cr} 1^{+/ G F P}$ group vs $11.2 \pm$ 1.7 rows in $\mathrm{rd10} / \mathrm{C} \times 3 \mathrm{cr} 1^{\text {GFP/GFP }}$ group; $n=10 ; p<0.01$; Fig. $10 F)$. Therefore, Cx3cr1 deficiency caused more rod loss in rd10 retinas. On the other hand, cone density was found to be comparable between $\mathrm{rd} 10 / \mathrm{C} \times 3 \mathrm{cr} 1^{+/ G F P}$ and $\mathrm{rd} 10 /$ CX3 crl $1^{\text {GFP/GFP }}$ mice at P25. However, cone morphology was severely damaged in $\mathrm{rd} 10 / \mathrm{C} \times 3 \mathrm{cr} 1^{G F P / G F P}$ mice. At P25, the IS of cones was seen in $\mathrm{rd} 10 / \mathrm{C} \times 3 \mathrm{cr} 1^{+/ G F P}$ mice (Fig. 10B), while cones had flattened ISs in $\mathrm{rd10} / \mathrm{C} \times 3 \mathrm{cr} 1^{\text {GFP/GFP }}$ mice (Fig. 10D). Moreover, the red/green-opsins were expressed primarily in the OS of cones. The cone axons and pedicles were positive for $\mathrm{red} /$ green-opsins in $\mathrm{rd10} / \mathrm{C} \times 3 \mathrm{cr} 1^{\text {GFP/GFP }}$ mice (Fig. 10D), while red/green-opsins were restricted to the ISs of cones in rd10/ $\mathrm{C} \times 3 \mathrm{cr} 1^{+/ G F P}$ mice. The redistribution of the red/green-opsins in cones is a sign of damage to cone photoreceptors (Haverkamp et al., 2005; Lin et al., 2009). The redistributions of the opsins in cones of rd10/ Cx3cr1 $1^{\text {GFP/GFP }}$ mice indicated the additional neurotoxic effect of $\mathrm{Cx} 3 \mathrm{cr} 1$ deficiency in cones.

To understand the mechanisms underlying the accelerated photoreceptor degeneration in $\mathrm{rd} 10 / \mathrm{C} \times 3 \mathrm{cr} 1^{\text {GFP/GFP }}$ mice, we examined the state of microglial activation. We found that $C \times 3 \mathrm{cr} 1$ deletion led to increased numbers of microglia/macrophages in the ONL when compared with $\mathrm{rd10} / \mathrm{C} \times 3 \mathrm{cr} 1^{+/ G F P}$ mice at both P16 and P19 (Fig. 10E), suggesting that Cx3cr1 deficiency dysregulated microglia activation in $\mathrm{rd} 10$ retinas. Therefore, the additional neurotoxic effect of $\mathrm{Cx} 3 \mathrm{cr} 1$ deficiency on photoreceptors in $\mathrm{rd} 10$ retinas was probably associated with increased inflammatory responses.

Furthermore, we tested whether $C x 3 c r 1$ deficiency affected minocycline treatment. We treated $\mathrm{rd10/C} \times 3 \mathrm{cr} 1^{\text {GFP/GFP }}$ mice with minocycline or PBS for $12 \mathrm{~d}$, starting from P13. We per- formed functional studies by measuring scotopic and photopic ERGs at P25. Compared with those treated with PBS, minocycline-treated $\mathrm{rd} 10 / \mathrm{C} \times 3 \mathrm{cr} 1^{\text {GFP/GFP }}$ mice had greater mean amplitudes of a- and b-waves under scotopic conditions $(p<$ 0.01 ; Fig. $11 A, B, D, E)$. A similar trend was also observed for average latency time for b-waves under scotopic conditions $(p<$ 0.01 ; Fig. $11 G, H)$. Under photopic condition, however, we found that b-waves did not differ between minocycline-treated and PBS-injected $\mathrm{rd} 10 / C \times 3 c r 1^{\text {GFP/GFP }}$ mice $(p>0.05$; Fig. $11 C, F)$, whereas a-wave amplitudes were significantly smaller in PBSinjected $\mathrm{rd} 10 / C \times 3 c r 1^{G F P / G F P}$ mice than in minocycline-injected rd10/Cx3 $c r 1^{G F P / G F P}$ mice $(p<0.05$; Fig. $11 C, F)$. We did not observe any change in average latency times for both a- and b-waves under photopic condition $(p>0.05$; Fig. $11 I)$. Therefore, minocycline treatment also delayed the progression of photoreceptor degeneration in Cx3crl-deficient rd10 retinas, indicating that minocycline exerted its neuroprotective effects through $C \times 3 c r 1$-independent mechanisms. 

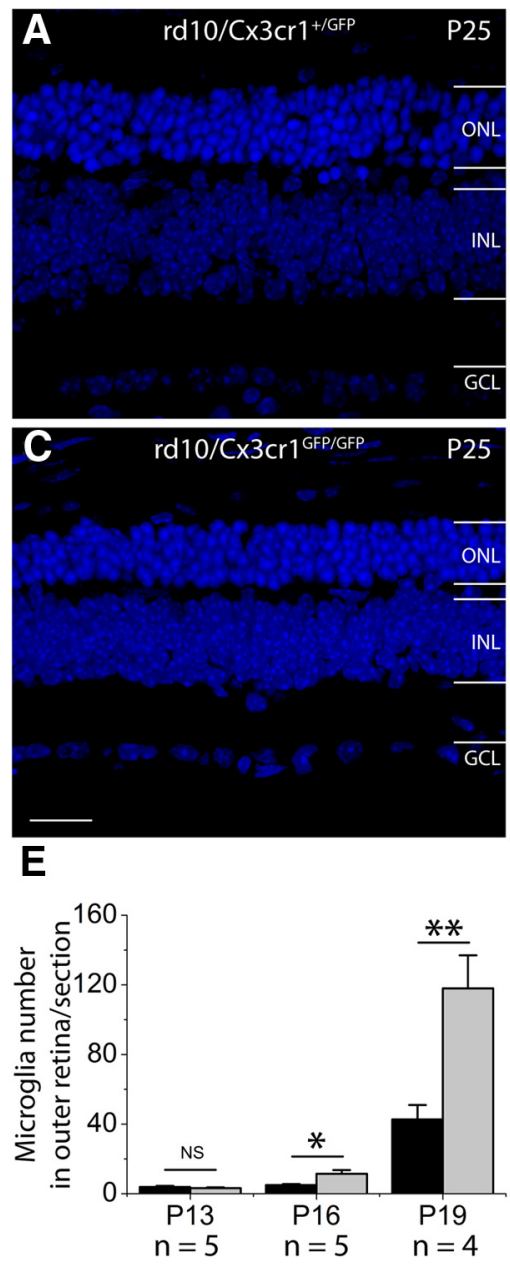

Figure 10. $\quad(x 3 \mathrm{cr} 1$ deficiency dysregulates microglia activation and increases photoreceptor apoptosis in rd10 retinas. $\boldsymbol{A}-\boldsymbol{D}, \mathbf{C} \times 3 \mathrm{Cr} 1$ deficiency caused more rod loss in rd10 retinas $(\boldsymbol{C})$ than in rd10 retinas with $(x 3 \mathrm{Cr} 1(\boldsymbol{A})$. At $\mathrm{P} 25$, cone photoreceptors in $\mathrm{rd} 10 / \mathrm{C} \times 3 \mathrm{Cr} 1^{+/ G F P}$ retinas maintain ISs $(\boldsymbol{B})$, and the ISs of cone photoreceptors in $\mathrm{rd} 10 / \mathrm{C} \times 3 \mathrm{Cr} 1^{\text {GFP/GFP }}$ retinas become flattened, and redistribution of red/green opsins ( $R / G$ opsin) to cell bodies and cone axonal terminals occurs in cones of $\mathrm{rd} 10 / \mathrm{C} \times 3 \mathrm{Cr}^{\text {GFP/GFP }}$ retinas (D). E, Quantification of microglial cells that migrated into the $0 \mathrm{NL}$ in vertical sections of rd10 retinas with or without $C \times 3 \mathrm{cr} 1$ deficiency at $\mathrm{P} 13, \mathrm{P} 16$, and $\mathrm{P} 19 . \boldsymbol{F}$, The $0 \mathrm{NL}$ thickness, measured by photoreceptor layers, is significantly different between rd10 retinas with or without $C \times 3 \mathrm{Cr} 1$ deficiency at both P19 and P25. Results are presented as means $\pm \mathrm{SD} ; n=$ number of retinas in each group, ${ }^{*} p<0.05$ and ${ }^{* *} p<0.01$. INL, inner nuclear layer; $\mathrm{GCL}$, ganglion cell layer; Scale bar, $20 \mu \mathrm{m}$.

\section{Discussion}

The main finding of this study was that microglia activation played pathological roles in the course of retinal degeneration in the rd10 mouse model of RP and inhibition of microglia activation by minocycline protected photoreceptors against apoptosis. First, we demonstrated that microglia activation was an early alteration in the rd10 retina, potentially contributing to disease progression. Second, suppression of microglia activation by minocycline and COX-1 specific inhibitor SC-560 resulted in reduction of both pro-inflammatory cytokines and pro-apoptotic mediators, leading to significant structural and functional preservation in rd10 retinas. Third, we identified that minocycline exerted its neuroprotective effects through both anti-apoptotic and anti-inflammatory mechanisms. Finally, we found that Cx3cr1 deficiency dysregulated microglia activation and subsequently increased photoreceptor vulnerability in rd10 mice, suggesting $\mathrm{Cx} 3 \mathrm{crl}$ might protect against microglial neurotoxicity. Collectively, our data demonstrated that activated microglia contributed to the severity of RP retinas. Therefore, modulating mi- croglia activation could be a potential treatment strategy aimed at improving photoreceptor survival in human RP.

Microglia activation has been reported to be an early event in the development of retinal degeneration (Roque et al., 1996; Gupta et al., 2003; Zeiss and Johnson, 2004; Zeng et al., 2005; Gehrig et al., 2007; Sasahara et al., 2008; Ebert et al., 2009; Zhou et al., 2011; Sheets et al., 2013; Yoshida et al., 2013a, b). Our data from rd10 retinas were in agreement with these previous reports. Microglia activation and infiltration in the subretinal space occurred in $\mathrm{rd} 10$ mice at P16, whereas photoreceptor apoptosis started at P19, 3 d later. To confirm whether microglia activation contributed to the progression of photoreceptor atrophy, we treated $\mathrm{rd} 10$ mice with minocycline from P13, before the initiation of microglia activation. Minocycline has been widely used as an inhibitor of microglial activation for different CNS neurodegenerative diseases (Yrjänheikki et al., 1998; Yong et al., 2004; Zhang et al., 2004; Fan et al., 2007; Lazarini et al., 2012; Schafer et al., 2012). Indeed, we observed that minocycline significantly reduced microglia activation and infiltration to the ONL in the rd10 retinas. Moreover, minocycline treatment significantly reduced TUNEL positivity and provided significant morphological preservation of photoreceptors throughout the retina. ERG recordings and optomotor responses further confirmed that minocycline treatment provided functional photoreceptor preservation in rd10 mice. These results provided clear evidence for the involvement of microglial activation in exacerbating photoreceptors' death in rd10 retinas. Similarly, inhibition of microglial activation using minocycline has been demonstrated in other experimental models of retinal degeneration caused by light (Kohno et al., 2013), subretinal hemorrhage (Zhao et al., 2011), and genetic impairments (rds mice; Hughes et al., 2004).

We identified that minocycline treatment exerted neuroprotective effects on photoreceptor apoptosis through two mechanisms. The first mechanism was through direct anti-apoptotic effect on photoreceptors. A previous study has reported that some of the photoreceptors in the ONL of rd10 retinas express an activated form of caspase-3 (Gargini et al., 2007). Similarly, the increased activity of caspase- 3 has also been reported in the $\mathrm{rd} 1$ mouse model of RP (Yoshizawa et al., 2002; Zeiss et al., 2004; Sharma and Rohrer, 2007). Minocycline has previously been shown to inhibit the caspase-3 activation (Chen et al., 2000; Hughes et al., 2004) and the release of cytochrome $c$ from the mitochondria in mice (Zhu et al., 2002). In agreement with previous findings, we found that expression level of caspase-3/7 protein was significantly increased in rd10 retinas. Administration of minocycline led to a significant reduction of caspase-3/7 and Bax proteins in rd10 retinas when compared 
with PBS-treated rd10 controls, which might reflect its direct action on photoreceptor apoptosis. Since comparable amounts of apoptotic photoreceptors were still observed in minocycline-treated rd10 retinas, we thus believed that its antiapoptotic effect might not be the primary mechanism involved in our study.

The second mechanism was through its anti-inflammatory effect. Previously, it has been reported that minocycline reduces microglial activation and improves neuronal survival in models of glaucoma, subretinal hemorrhage, and rds mice (Yang et al., 2007; Bosco et al., 2008; Zhao et al., 2011). Similarly, minocycline has been shown to prevent microglial activation against cerebral ischemia and Parkinson's disease (Yrjänheikki et al., 1999; Wu et al., 2002). Consistent with previous findings, we also observed suppression of microglia activation and reduction of proinflammatory cytotoxic mediator TNF- $\alpha$, COX-1, and COX-2 in rd10 retinas following minocycline treatment.

Moreover, inhibition of microglial activation using minocycline resulted from the partial inhibition of COX-1 and COX-2 induction, key enzymes involved in the production of pro-inflammatory prostanoids (García-Bueno et al., 2009; Griffin et al., 2013; Jiang et al., 2013). The upregulation of COX-2 has been demonstrated in other chronic neurodegenerative diseases, such as Parkinson's disease (Teismann et al., 2003a,b; Choi et al., 2009). Moreover, it has been shown that genetic deletion or pharmacological inhibition of COX-2 increases survival of dopaminergic neurons in animal models of Parkinson's disease (Teismann et al., 2003a). Here we showed that COX-2 protein level was upregulated in $\mathrm{rd} 10$ retinas. After minocycline treatment, we observed a significant reduction of COX-2 protein. COX-1 has been reported to facilitate neuroinflammatory processes in several models of neurodegenerative disorders (García-Bueno et al., 2009; Griffin et al., 2013). Genetic deletion or pharmacological inhibition of COX-1 attenuates inflammatory response and neuronal damage (Choi et al., 2008; Choi and Bosetti, 2009; García-Bueno et al., 2009; Griffin et al., 2013). Minocycline treatment led to a significant reduction of COX-1 protein in $\mathrm{rd} 10$ retinas. Therefore, minocycline might partially inhibit COX-1 and COX-2 activation, which led to the reduction of microglial-derived mediators and survival of photoreceptors.

It has been proposed that $\mathrm{Cx} 3 \mathrm{cl} 1 / \mathrm{Cx} 3 \mathrm{cr} 1$ signaling pathway regulates the communication of microglia with neurons in the nervous system (Harrison et al., 1998). However, the studies on the $\mathrm{Cx} 3 \mathrm{cl} 1 / \mathrm{Cx} 3 \mathrm{cr} 1$ pathway in neurological disorders produced contrasting results. $\mathrm{C} \times 3 \mathrm{cr} 1 \mathrm{knock}$-out has been shown to either increase (Meucci et al., 2000; Cardona et al., 2006) or decrease (Fuhrmann et al., 2010) neurotoxicity in several models of the CNS insult. We found that C $\times 3$ cr 1 deficiency led to an increased accumulation of activated microglia in the ONL and increased photoreceptor vulnerability, which was confirmed by scotopic and photopic ERGs (Fig. 9) and immunocytochemistry (Fig. 10). Less ONL were observed in $\mathrm{rd} 10$ mice without $\mathrm{C} \times 3 \mathrm{cr} 1$ than in
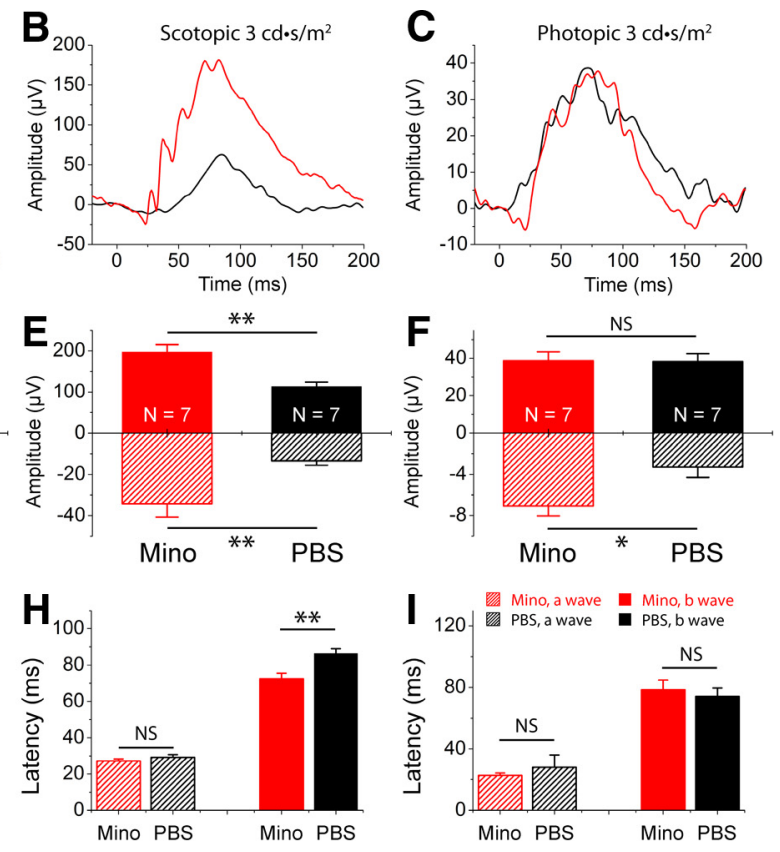

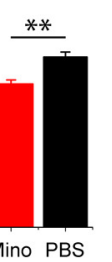

inocycline (Mino) treatment. $\boldsymbol{A}-\boldsymbol{B}$, Representative scotopic ERG responses to 0.01 and $3 \mathrm{~cd}-\mathrm{s} / \mathrm{m}^{2}$ light intensities from $\mathrm{rd} 10$ mice treated with minocycline (red curves) are expressed as the mean \pm SD. $n=$ animal numbers; ${ }^{* *} p<0.01$.

rd10 mice with $C \times 3 c r 1$, suggesting $C \times 3 c r 1$ deficiency caused additional rod loss. However, similar a-wave amplitudes under scotopic conditions were observed in rd10 mice with or without Cx3cr1 at P25 (Fig. 9). Given the fact that the majority of photoreceptors degenerated by P25 in the rd10 retina (Gargini et al., 2007), which largely contributed to the dramatic reduction in the a-wave, it was not surprising that additional rod loss in $\mathrm{C} \times 3 \mathrm{cr} 1$ deficient rd10 mice did not cause any significant change in a-wave amplitudes by P25. A significant drop in the ONL was observed in rd10 mice without $C \times 3$ cr 1 by P19 (Fig. 10F). After the peak of rod death, the difference in the ONL thickness was narrowed between rd10 mice with or without $C \times 3 c r 1$ by P25 (Fig. $10 F)$. Therefore, the loss of more ONL rows in rd10 mice without CX3cr1 by $\mathrm{P} 25$ did not cause any further significant reduction in a-wave amplitudes. On the other hand, although $C \times 3 \mathrm{cr} 1 \mathrm{defi}-$ ciency did not result in any cone loss in rd10 mice, it did exacerbate morphological changes and functional loss of cones. Photopic ERG b-wave amplitudes were significantly smaller when compared with rd10 without Cx3cr1 deficiency. The $\mathrm{Cx} 3 \mathrm{cl} 1 / \mathrm{Cx} 3 \mathrm{cr} 1$ signaling pathway appeared to restrain microglia activation in rd10 retinas, and $C \times 3$ crl deficiency resulted in extra microglia activation. The activated $C \times 3 \mathrm{cr} 1$-deficient microglia had an additional neurotoxic effect on photoreceptor survival in rd10 retinas.

In summary, our study provided strong support to the concept that activated microglia were important contributors to the overall apoptosis of photoreceptors in $\mathrm{rd} 10$ retinas. The suppression of microglia activation by minocycline or SC-560 reduced microglia-mediated photoreceptor death. Our data suggested that therapeutic interventions aimed at preventing the loss of photoreceptor cells can be through the inhibition of microglia activation. 


\section{References}

Block ML, Zecca L, Hong JS (2007) Microglia-mediated neurotoxicity: uncovering the molecular mechanisms. Nat Rev Neurosci 8:57-69. CrossRef Medline

Bosco A, Inman DM, Steele MR, Wu G, Soto I, Marsh-Armstrong N, Hubbard WC, Calkins DJ, Horner PJ, Vetter ML (2008) Reduced retina microglial activation and improved optic nerve integrity with minocycline treatment in the DBA/2J mouse model of glaucoma. Invest Ophthalmol Vis Sci 49:1437-1446. CrossRef Medline

Cardona AE, Pioro EP, Sasse ME, Kostenko V, Cardona SM, Dijkstra IM, Huang D, Kidd G, Dombrowski S, Dutta R, Lee JC, Cook DN, Jung S, Lira SA, Littman DR, Ransohoff RM (2006) Control of microglial neurotoxicity by the fractalkine receptor. Nat Neurosci 9:917-924. CrossRef Medline

Chen M, Ona VO, Li M, Ferrante RJ, Fink KB, Zhu S, Bian J, Guo L, Farrell LA, Hersch SM,Hobbs W, Vonsattel JP, Cha JH, Friedlander RM (2000) Minocycline inhibits caspase- 1 and caspase- 3 expression and delays mortality in a transgenic mouse model of Huntington disease. Nat Med 6:797801. CrossRef Medline

Choi SH, Bosetti F (2009) Cyclooxygenase-1 null mice show reduced neuroinflammation in response to beta-amyloid. Aging 1:234-244. Medline

Choi SH, Langenbach R, Bosetti F (2008) Genetic deletion or pharmacological inhibition of cyclooxygenase- 1 attenuate lipopolysaccharide-induced inflammatory response and brain injury. FASEB J 22:1491-1501. Medline

Choi SH, Aid S, Bosetti F (2009) The distinct roles of cyclooxygenase-1 and -2 in neuroinflammation: implications for translational research. Trends Pharmacol Sci 30:174-181. CrossRef Medline

Combadière C, Feumi C, Raoul W, Keller N, Rodéro M, Pézard A, Lavalette S, Houssier M, Jonet L, Picard E, Debré P, Sirinyan M, Deterre P, Ferroukhi T, Cohen SY, Chauvaud D, Jeanny JC, Chemtob S, Behar-Cohen F, Sennlaub F (2007) CX3CR1-dependent subretinal microglia cell accumulation is associated with cardinal features of age-related macular degeneration. J Clin Invest 117:2920-2928. CrossRef Medline

Ebert S, Weigelt K, Walczak Y, Drobnik W, Mauerer R, Hume DA, Weber BH, Langmann T (2009) Docosahexaenoic acid attenuates microglial activation and delays early retinal degeneration. J Neurochem 110:1863-1875. CrossRef Medline

Fan R, Xu F, Previti ML, Davis J, Grande AM, Robinson JK, Van Nostrand WE (2007) Minocycline reduces microglial activation and improves behavioral deficits in a transgenic model of cerebral microvascular amyloid. J Neurosci 27:3057-3063. CrossRef Medline

Fuhrmann M, Bittner T, Jung CK, Burgold S, Page RM, Mitteregger G, Haass C, LaFerla FM, Kretzschmar H, Herms J (2010) Microglial Cx3cr1 knockout prevents neuron loss in a mouse model of Alzheimer's disease. Nat Neurosci 13:411-413. CrossRef Medline

García-Bueno B, Serrats J, Sawchenko PE (2009) Cerebrovascular cyclooxygenase-1 expression, regulation, and role in hypothalamicpituitary-adrenal axis activation by inflammatory stimuli. J Neurosci 29: 12970-12981. CrossRef Medline

Gargini C, Terzibasi E, Mazzoni F, Strettoi E (2007) Retinal organization in the retinal degeneration $10(\mathrm{rd} 10)$ mutant mouse: a morphological and ERG study. J Comp Neurol 500:222-238. CrossRef Medline

Gehrig A, Langmann T, Horling F, Janssen A, Bonin M, Walter M, Poths S, Weber BH (2007) Genome-wide expression profiling of the retinoschisindeficient retina in early postnatal mouse development. Invest Ophthalmol Vis Sci 48:891-900. CrossRef Medline

Glass CK, Saijo K, Winner B, Marchetto MC, Gage FH (2010) Mechanisms underlying inflammation in neurodegeneration. Cell 140:918-934. CrossRef Medline

Griffin ÉW, Skelly DT, Murray CL, Cunningham C (2013) Cyclooxygenase-1dependent prostaglandins mediate susceptibility to systemic inflammationinduced acute cognitive dysfunction. J Neurosci 33:15248-15258. CrossRef Medline

Gupta N, Brown KE, Milam AH (2003) Activated microglia in human retinitis pigmentosa, late-onset retinal degeneration, and age-related macular degeneration. Exp Eye Res 76:463-471. CrossRef Medline

Hanisch UK, Kettenmann H (2007) Microglia: active sensor and versatile effector cells in the normal and pathologic brain. Nat Neurosci 10:13871394. CrossRef Medline

Harrison JK, Jiang Y, Chen S, Xia Y, Maciejewski D, McNamara RK, Streit WJ, Salafranca MN, Adhikari S, Thompson DA, Botti P, Bacon KB, Feng L (1998) Role for neuronally derived fractalkine in mediating interactions between neurons and CX3CR1-expressing microglia. Proc Natl Acad Sci U S A 95:10896-10901. CrossRef Medline

Hartong DT, Berson EL, Dryja TP (2006) Retinitis pigmentosa. Lancet 368: 1795-1809. CrossRef Medline

Haverkamp S, Wässle H, Duebel J, Kuner T, Augustine GJ, Feng G, Euler T (2005) The primordial, blue-cone color system of the mouse retina. J Neurosci 25:5438-5445. CrossRef Medline

Hughes EH, Schlichtenbrede FC, Murphy CC, Broderick C, van Rooijen N, Ali RR, Dick AD (2004) Minocycline delays photoreceptor death in the rds mouse through a microglia-independent mechanism. Exp Eye Res 78:1077-1084. CrossRef Medline

Iwakabe H, Katsuura G, Ishibashi C, Nakanishi S (1997) Impairment of pupillary responses and optokinetic nystagmus in the mGluR6-deficient mouse. Neuropharmacology 36:135-143. CrossRef Medline

Jiang J, Quan Y, Ganesh T, Pouliot WA, Dudek FE, Dingledine R (2013) Inhibition of the prostaglandin receptor EP2 following status epilepticus reduces delayed mortality and brain inflammation. Proc Natl Acad Sci U S A 110:3591-3596. CrossRef Medline

Kohno H, Chen Y, Kevany BM, Pearlman E, Miyagi M, Maeda T, Palczewski K, Maeda A (2013) Photoreceptor proteins initiate microglial activation via Toll-like receptor 4 in retinal degeneration mediated by all-transretinal. J Biol Chem 288:15326-15341. CrossRef Medline

Langmann T (2007) Microglia activation in retinal degeneration. J Leukoc Biol 81:1345-1351. CrossRef Medline

Lazarini F, Gabellec MM, Torquet N, Lledo PM (2012) Early activation of microglia triggers long-lasting impairment of adult neurogenesis in the olfactory bulb. J Neurosci 32:3652-3664. CrossRef Medline

Liang KJ, Lee JE, Wang YD, Ma W, Fontainhas AM, Fariss RN, Wong WT (2009) Regulation of dynamic behavior of retinal microglia by CX3CR1 signaling. Invest Ophthalmol Vis Sci 50:4444-4451. CrossRef Medline

Lin B, Masland RH, Strettoi E (2009) Remodeling of cone photoreceptor cells after rod degeneration in rd mice. Exp Eye Res 88:589-599. CrossRef Medline

Lucin KM, Wyss-Coray T (2009) Immune activation in brain aging and neurodegeneration: too much or too little? Neuron 64:110-122. CrossRef Medline

Meucci O, Fatatis A, Simen AA, Miller RJ (2000) Expression of CX3CR1 chemokine receptors on neurons and their role in neuronal survival. Proc Natl Acad Sci U S A 97:8075-8080. CrossRef Medline

Prusky GT, Alam NM, Beekman S, Douglas RM (2004) Rapid quantification of adult and developing mouse spatial vision using a virtual optomotor system. Invest Ophthalmol Vis Sci 45:4611-4616. CrossRef Medline

Roque RS, Imperial CJ, Caldwell RB (1996) Microglial cells invade the outer retina as photoreceptors degenerate in Royal College of Surgeons rats. Invest Ophthalmol Vis Sci 37:196-203. Medline

Saijo K, Glass CK (2011) Microglial cell origin and phenotypes in health and disease. Nat Rev Immunol 11:775-787. CrossRef Medline

Sasahara M, Otani A, Oishi A, Kojima H, Yodoi Y, Kameda T, Nakamura H, Yoshimura N (2008) Activation of bone marrow-derived microglia promotes photoreceptor survival in inherited retinal degeneration. Am J Pathol 172:1693-1703. CrossRef Medline

Schafer DP, Lehrman EK, Kautzman AG, Koyama R, Mardinly AR, Yamasaki R, Ransohoff RM, Greenberg ME, Barres BA, Stevens B (2012) Microglia sculpt postnatal neural circuits in an activity and complementdependent manner. Neuron 74:691-705. CrossRef Medline

Sharma AK, Rohrer B (2007) Sustained elevation of intracellular cGMP causes oxidative stress triggering calpain-mediated apoptosis in photoreceptor degeneration. Curr Eye Res 32:259-269. CrossRef Medline

Sheets KG, Jun B, Zhou Y, Zhu M, Petasis NA, Gordon WC, Bazan NG (2013) Microglial ramification and redistribution concomitant with the attenuation of choroidal neovascularization by neuroprotectin D1. Mol Vis 19:1747-1759. Medline

Shen D, Cao X, Zhao L, Tuo J, Wong WT, Chan CC (2011) Naloxone ameliorates retinal lesions in $\mathrm{Ccl} 2 / \mathrm{Cx} 3 \mathrm{cr} 1$ double-deficient mice via modulation of microglia. Invest Ophthalmol Vis Sci 52:2897-2904. CrossRef Medline

Teismann P, Tieu K, Choi DK, Wu DC, Naini A, Hunot S, Vila M, JacksonLewis V, Przedborski S (2003a) Cyclooxygenase-2 is instrumental in Parkinson's disease neurodegeneration. Proc Natl Acad Sci U S A 100: 5473-5478. CrossRef Medline

Teismann P, Vila M, Choi DK, Tieu K, Wu DC, Jackson-Lewis V, Przedborski 
S (2003b) COX-2 and neurodegeneration in Parkinson's disease. Ann N Y Acad Sci 991:272-277. Medline

Umino Y, Solessio E, Barlow RB (2008) Speed, spatial, and temporal tuning of rod and cone vision in mouse. J Neurosci 28:189-198. CrossRef Medline

Wu DC, Jackson-Lewis V, Vila M, Tieu K, Teismann P, Vadseth C, Choi DK, Ischiropoulos H, Przedborski S (2002) Blockade of microglial activation is neuroprotective in the 1-methyl-4-phenyl-1,2,3,6-tetrahydropyridine mouse model of Parkinson disease. J Neurosci 22:1763-1771. Medline

Xiao J, Ching YP, Liong EC, Nanji AA, Fung ML, Tipoe GL (2013) Garlicderived S-allylmercaptocysteine is a hepato-protective agent in nonalcoholic fatty liver disease in vivo animal model. Eur J Nutr 52:179-191. CrossRef Medline

Yang LP, Li Y, Zhu XA, Tso MO (2007) Minocycline delayed photoreceptor death in rds mice through iNOS-dependent mechanism. Mol Vis 13: 1073-1082. Medline

Yong VW, Wells J, Giuliani F, Casha S, Power C, Metz LM (2004) The promise of minocycline in neurology. Lancet Neurol 3:744-751. CrossRef Medline

Yoshida N, Ikeda Y, Notomi S, Ishikawa K, Murakami Y, Hisatomi T, Enaida $\mathrm{H}$, Ishibashi T (2013a) Clinical evidence of sustained chronic inflammatory reaction in retinitis pigmentosa. Ophthalmology 120:100-105. CrossRef Medline

Yoshida N, Ikeda Y, Notomi S, Ishikawa K, Murakami Y, Hisatomi T, Enaida H, Ishibashi T (2013b) Laboratory evidence of sustained chronic inflammatory reaction in retinitis pigmentosa. Ophthalmology 120:e5-e12. CrossRef Medline

Yoshizawa K, Kiuchi K, Nambu H, Yang J, Senzaki H, Kiyozuka Y, Shikata N, Tsubura A (2002) Caspase-3 inhibitor transiently delays inherited retinal degeneration in $\mathrm{C} 3 \mathrm{H}$ mice carrying the rd gene. Graefes Arch Clin Exp Ophthalmol 240:214-219. CrossRef Medline

Yrjänheikki J, Keinänen R, Pellikka M, Hökfelt T, Koistinaho J (1998) Tetracyclines inhibit microglial activation and are neuroprotective in global brain ischemia. Proc Natl Acad Sci U S A 95:15769-15774. CrossRef Medline

Yrjänheikki J, Tikka T, Keinänen R, Goldsteins G, Chan PH, Koistinaho J (1999) A tetracycline derivative, minocycline, reduces inflammation and protects against focal cerebral ischemia with a wide therapeutic window. Proc Natl Acad Sci U S A 96:13496-13500. CrossRef Medline

Zeiss CJ, Johnson EA (2004) Proliferation of microglia, but not photoreceptors, in the outer nuclear layer of the rd-1 mouse. Invest Ophthalmol Vis Sci 45:971-976. CrossRef Medline

Zeiss CJ, Neal J, Johnson EA (2004) Caspase-3 in postnatal retinal development and degeneration. Invest Ophthalmol Vis Sci 45:964-970. CrossRef Medline

Zeng HY, Zhu XA, Zhang C, Yang LP, Wu LM, Tso MO (2005) Identification of sequential events and factors associated with microglial activation, migration, and cytotoxicity in retinal degeneration in rd mice. Invest Ophthalmol Vis Sci 46:2992-2999. CrossRef Medline

Zhang C, Lei B, Lam TT, Yang F, Sinha D, Tso MO (2004) Neuroprotection of photoreceptors by minocycline in light-induced retinal degeneration. Invest Ophthalmol Vis Sci 45:2753-2759. CrossRef Medline

Zhao L, Ma W, Fariss RN, Wong WT (2011) Minocycline attenuates photoreceptor degeneration in a mouse model of subretinal hemorrhage microglial: inhibition as a potential therapeutic strategy. Am J Pathol 179: 1265-1277. CrossRef Medline

Zhou Y, Sheets KG, Knott EJ, Regan CE Jr, Tuo J, Chan CC, Gordon WC, Bazan NG (2011) Cellular and 3D optical coherence tomography assessment during the initiation and progression of retinal degeneration in the Ccl2/Cx3cr1-deficient mouse. Exp Eye Res 93:636-648. CrossRef Medline

Zhu S, Stavrovskaya IG, Drozda M, Kim BY, Ona V, Li M, Sarang S, Liu AS, Hartley DM, Wu DC, Gullans S, Ferrante RJ, Przedborski S, Kristal BS, Friedlander RM (2002) Minocycline inhibits cytochrome c release and delays progression of amyotrophic lateral sclerosis in mice. Nature 417: 74-78. CrossRef Medline 